\title{
Low Fidelity Simulation on Sensory Impairments in Older Adults: Undergraduate Nursing Students' Self-Reported Perceptions on Learning
}

\author{
Ronie Walters $\left.{ }^{(}\right)$, Leah Macaden* ${ }^{\circledR}$, Abbi Tracey ${ }^{\circledR}$, Annetta Smith \\ Department of Nursing and Midwifery, University of the Highlands and Islands, Centre for Health Science, Inverness, Scotland \\ Email: *leah.macaden@uhi.ac.uk
}

How to cite this paper: Walters, R., Macaden, L., Tracey, A. and Smith, A. (2021) Low Fidelity Simulation on Sensory Impairments in Older Adults: Undergraduate Nursing Students' Self-Reported Perceptions on Learning. Open Journal of Nursing, 11, 89-103.

https://doi.org/10.4236/ojn.2021.113009

Received: February 4, 2021

Accepted: March 8, 2021

Published: March 11, 2021

Copyright $\odot 2021$ by author(s) and Scientific Research Publishing Inc. This work is licensed under the Creative Commons Attribution International License (CC BY 4.0).

http://creativecommons.org/licenses/by/4.0/

\begin{abstract}
Globally, the population is living longer and by 2050 , it is predicted to reach 2.1 billion people. Sensory and cognitive impairments are common long-term conditions among older Europeans and have considerable functional, social, emotional and economic impacts on the individual and those caring for them. Nurses have frequent encounters with patients with these impairments and are expected to prioritise people, assess their needs and accommodate practice to meet these needs. In order to develop the requisite knowledge and understanding to support people living with these impairments, student nurses require an immersive and experiential approach to learning as opposed to just information transfer. This study reports on a cross-sectional analysis of a low fidelity simulation on sensory impairments as part of a wider dementia curriculum in semester one of the undergraduate nursing programme at the University of Highlands and Islands. Findings from an online questionnaire-based survey and content analysis of free text responses revealed that students found the simulation activities critical for gaining subject knowledge, understanding and insight. This study concluded that low-fidelity simulation of sensory/cognitive impairments, within the context of a broader curriculum of supportive activities, can be effective at developing relevant knowledge, understanding and gaining insights in this subject area among undergraduate nursing students.
\end{abstract}

\section{Keywords}

Low Fidelity, Simulation, Sensory/Cognitive Impairments, Nurse Education, Empathy 


\section{Background}

The global population is experiencing increasing longevity. In 2017, the global population of people aged $>60$ years had more than doubled since 1980 and was recorded at 962 million. By 2050, this number is predicted to double again and reach 2.1 billion people [1]. Despite this significant demographic change, evidence demonstrates that negative attitudes towards ageing can prevent inclusion and participation and be more commonly displayed in the presence of affective disorders, physical challenges, and age-related conditions, such as sensory or cognitive impairments [2].

Sensory impairment is one of the most common chronic conditions of later life. More than 2.2 billion people have vision impairments or blindness [3], and 466 million have disabling hearing loss [4]. Around 50 million people worldwide have dementia, with 10 million people diagnosed with dementia annually leading to an estimated prevalence of 152 million by 2050 [5].

Sensory and cognitive impairments have considerable functional, social and emotional and economic impacts on both the individual and those caring for them [6]. Such impairments can make navigating healthcare systems more challenging and can result in poor outcomes of care [7] [8]. Older patients are more likely to have multimorbidity and carry an increased treatment burden via multiple appointments, medications and associated needs, yet struggle to access healthcare on a parity with those without disabilities [9] [10]. Life altering conditions, such as cognitive and sensory impairments, are often not immediately visible, and therefore the challenges that they bring are not always readily appreciated [7].

Conclusive evidence exists to demonstrate that hearing and vision impairments significantly influence the ability to carry out activities of daily living (ADL) [11] [12] [13] [14] and increase the risk of falls, loneliness and social isolation [15] [16]. This can be further exacerbated in patients who are also cognitively impaired and find themselves in unfamiliar healthcare environments. Nurses are frontline health care professionals providing care to this vulnerable patient group and should therefore possess the necessary knowledge, skills and attitudes to provide safe, empathetic and dignified care.

The values of kindness, respect, empathy and compassion are integral to nursing practice. Nurses are expected to prioritise people, uphold their dignity, assess and respond to physical, social and psychological needs and adapt practice to accommodate the needs of the individual [17]. The development of such understanding and empathy requires more than information transfer. Empathy is a multi-dimensional construct, an essential element of therapeutic relationships and patient-centred communication. Empathy involves two distinct aspects: the ability to understand and see the world from others' perspectives (cognitive empathy) and the ability to connect to others' experiences or feelings (affective empathy) [18].

Yet, healthcare is becoming less empathic and empathy can decline in health- 
care students throughout the duration of the degree programme [19]. A review by Levett-Jones et al. [20] examined the effectiveness of interventions to increase empathy in nursing students and found mixed results. However, immersive and simulation-based learning methods were found to be effective at least in the short term [2] recommending simulation as a potential mechanism to improve understanding and empathy with regard to ageing. When learning occurs in "close to real" environments, the learning is more likely to be remembered and reproduced [21]. Indeed, simulation in various forms is widely used throughout healthcare education and is endorsed as an essential component of pre-registration nursing curricula [22]. Simulation as a pedagogical approach is interesting, interactive and effective, and allows multiple learning objectives to be taught without risking patient harm [23] [24] [25]. In addition to facilitating experiential learning, simulation helps to incorporate the affective (emotional) component of learning [26]. Simulation-based healthcare education is recognised as a powerful intervention to increase professional competence with transferrable skills to improve patient care [27] [28]. However, much of the evidence to support the use of simulation in nursing education focuses on moderate to high fidelity clinical scenario-based learning. Evidence on low fidelity simulation and simulation on sensory and cognitive impairments is scant [27].

\section{Simulation on Sensory Impairments}

Hearing, vision and cognitive disorders are common chronic conditions amongst older Europeans and studies document their high co-occurrence [29] [30]. 300 pre-registration nursing students were trained using a 90-minute low fidelity simulation on sensory impairments as part of a wider dementia curriculum in semester one of the undergraduate nursing programme at the University of Highlands and Islands between 2017 and 2019. Students rotate through six learning stations, with each station having a clearly outlined activity involving at least two or more sensory impairments. Students experience a combination of either visual, hearing, taste, smell or peripheral sensory impairments (Table 1) using low-fidelity equipment. Two of the stations included some simulated aspects on cognitive impairment and students were also asked to think about living with dementia in addition to sensory impairments as they worked through each station. A small group of four students completed guided discussion and reflection at each station. At the end of the 90-minute session, debrief was facilitated by two facilitators with all 24 students ( 6 groups of four students in each group) and focused in detail on emotions experienced, new knowledge and insights gained on both sensory/cognitive impairments and their relevance to practice. The simulation was described in depth in a previous paper [31] and included anecdotal evidence of benefit from a single cohort of students. This study aimed to identify the influence and relevance of a low fidelity simulation on sensory impairments in older adults for undergraduate nurse education through students' self-reported perceptions on learning using this pedagogical approach from three cohorts (2017, 2018 and 2019). 
Table 1. Simulation stations on sensory and cognitive impairments in older adults.

\begin{tabular}{lll}
\hline Station & Simulation Focus & Activities \\
\hline 1. & $\begin{array}{l}\text { Vision, hearing and } \\
\text { cognitive impairments }\end{array}$ & $\begin{array}{l}\text { Reading the newspaper, completing a crossword puzzle, filling out a registration form in a different language } \\
\text { (to simulate the co-existence of sensory \& cognitive impairment/s) using sim specs that replicate a number of } \\
\text { vision impairments such as retinal haemorrhage, field deficits, macular degeneration and ear plugs. }\end{array}$ \\
2. & $\begin{array}{l}\text { Vision and peripheral } \\
\text { sensory impairments }\end{array}$ & $\begin{array}{l}\text { Sorting out buttons of different colours, sizes and shapes } \\
\text { (to simulate medicines management and polypharmacy). }\end{array}$ \\
3. & $\begin{array}{l}\text { Vision, cognitive and } \\
\text { mobility impairments }\end{array}$ & $\begin{array}{l}\text { Setting the table for two people using white and coloured/crockery cutlery } \\
\text { (to simulate the importance of design and contrast). }\end{array}$ \\
4. & $\begin{array}{l}\text { Vision and gustatory } \\
\text { impairments }\end{array}$ & Being blindfolded and fed with familiar flavours and textures of food. \\
5. & $\begin{array}{l}\text { Vision and olfactory } \\
\text { impairments }\end{array}$ & An aroma guessing activity whilst being blindfolded and wearing nose plugs. \\
6. & The Solutions Corner & Display of a range of sensory aids to support people living with sensory/cognitive impairments.
\end{tabular}

\section{Methods}

\subsection{Research Design}

Cross sectional survey.

\subsection{Aim}

The aim of this study was to identify the influence and relevance of a low fidelity simulation on sensory impairments in older adults for undergraduate nurse education through students' self-reported perceptions on learning using this pedagogical approach.

\subsection{Participants}

95 undergraduate nursing students representing three cohorts.

\subsection{Inclusion Criteria}

Students who had participated in the simulation training as part of the wider dementia curriculum.

\subsection{Data Collection}

Three cohort years of undergraduate nursing students were invited to participate in the study following a short presentation on the project to each cohort and an announcement via the University's Virtual Learning Environment (VLE). Students had varying practice learning experience depending on their cohort year first, second and third-year students had completed one, four and five placements for their practice learning respectively. Access to participant information sheets, consent forms and the online survey were made available. The survey link was provided to all cohorts via the VLE. Participants were required to provide consent online prior to being able to access the questionnaire for completion.

Data was collected using the Jisc online survey between Jan and April 2020. 
The questionnaire was designed by the research team to reflect the intended learning outcomes and evidence from the literature on this pedagogical approach. The questionnaire used a Likert scale with responses ranging from 1 (not at all) to 10 (most certainly) to capture the influence and relevance of this pedagogical approach on students' knowledge, understanding, confidence and insights into caring for older people with sensory impairments (sight, hearing, dual, taste, smell and sense of touch), cognitive impairments and on students' professional values. Free-text responses allowed students to describe their application of knowledge to practice.

\subsection{Data Analysis}

Data reported in this study are from the online survey and content analysis of free-text responses from 95 student responses representing three cohorts of the undergraduate nursing programme. Quantitative data were analysed using simple descriptive statistics, frequencies, and comparison of means.

Qualitative insights and themes reported here are from a content analysis conducted on the free-text responses using Ketso [32] to help identify and develop themes. Ketso [32] is a data-collection method designed for use in participatory research methods and comprises colourful leaves, branches and icons that can be organised onto felt mats. Each free text-response was written onto a Ketso leaf and then grouped into emerging themes. The kit allowed for easy visualization of themes and re-organisation by researchers following discussion. The themes were then refined independently by two researchers (AT, RW) in three rounds of consolidation.

\subsection{Ethics}

The study had ethical approval from the University of the Highlands and Islands Research Ethics Committee (REC No: OLETHEO1827 dated 02 Aug 2019).

\section{Results}

\subsection{Quantitative Analysis}

Most of the students who completed the survey were in their first two years of the programme (89.4.9\%) with a wide range of practice learning experience (see Table 2). $60 \%$ of students had previous experience as a Health Care Assistant (HCA) and $49.5 \%$ had previous experience of sensory/cognitive impairments through caring for friends or family members. Whilst on placement, $87.4 \%$ of students indicated they had cared for patients with sensory impairment and 98.9\% had cared for someone with a cognitive impairment.

\subsubsection{Perceived Efficacy of the Simulation}

Students rated the simulation most certainly (with a score of 10 on the Likert scale) influenced their understanding on the needs of people with sensory impairment (36.8\%) and cognitive impairment (42.1\%) (see Table 3). $87.4 \%$ of students reported that the simulation facilitated new insights into sensory and 
cognitive impairments. Students reported that the simulation influenced their knowledge of the difficulties encountered by older adults with cognitive or sensory impairments with mean scores of 8.39 (cognitive) and 8.67 (sensory) respectively. Simulation on the impaired sense of touch was perceived to be most useful in practice (mean 8.21). Compassion and respecting choice were identified as the most influenced professional values (mean 9.04) closely followed by supporting inclusion (mean 9.03).

\subsubsection{Influence on Students' Learning}

The simulation was perceived to be critical to students' learning on the subject with a mean of 8.62 (SD 2.027) with $50.5 \%$ of students rating it $10 / 10$ and only $5.3 \%$ rating it below $5 / 10$.

To assess the influence of the simulation across the cohorts, data from $2^{\text {nd }}$ and $3^{\text {rd }}$ year students were grouped together $(n=39)$ and compared with first year $(n$ = 56) using a Mann-Whitney $U$ test (due to non-normal distributions). There were no differences between the groups with regards to knowledge and understanding gained (see Table 4 ), however, $2^{\text {nd }}$ and $3^{\text {rd }}$ year students (median $=10$ ) differed significantly from first year students (median $=9$ ) in their scores in identifying the simulation as being critical for learning, $U=1348, Z=2.087, p=$ 0.037 .

Table 2. Participants' information.

\begin{tabular}{|c|c|}
\hline Year: n (\%) & \\
\hline First & $56(58.9)$ \\
\hline Second & $29(30.5)$ \\
\hline Third & $10(10.5)$ \\
\hline Field: $\mathrm{n}(\%)$ & \\
\hline Adult & $72(75.8)$ \\
\hline Mental Health & $23(24.2)$ \\
\hline Placement type: $\mathrm{n}(\%)$ & \\
\hline Hospital - adult & $69(72.6)$ \\
\hline Hospital - mental health & $20(21.1)$ \\
\hline Community - adult & $38(40)$ \\
\hline Community - mental health & $26(27.4)$ \\
\hline Care home & $8(8.4)$ \\
\hline Hospice & $1(1.1)$ \\
\hline Previous experience: $\mathbf{n}(\%)$ & \\
\hline Previous experience as HCA & $57(60)$ \\
\hline Previous experience of caring for a family/friend with sensory/cognitive impairments & $47(49.5)$ \\
\hline Practice Learning Experience of caring $n$ (\%) & \\
\hline People with Sensory impairment & $83(87.4)$ \\
\hline People with Cognitive impairment & $94(98.9)$ \\
\hline
\end{tabular}


Table 3. Mean scores.

On a scale of 1 (not at all) to 10 (most certainly) to what extent did participation: Mean (SD)

\begin{tabular}{llll}
\hline $\begin{array}{l}\text { Help you understand the needs of people with the following types of } \\
\text { impairment: }\end{array}$ & $\begin{array}{l}\text { Sight } \\
8.49(1.850)\end{array}$ & $\begin{array}{l}\text { Hearing } \\
\text { Cognitive }\end{array}$ \\
Percentage rating simulation $10 / 10$ & $41.1 \%$ & $35.8 \%$ & $8.44(1.911)$ \\
\hline
\end{tabular}

On a scale of 1 (not at all) to 10 (most certainly) to what extent did participation: Mean (SD)

\begin{tabular}{llll}
\hline Influence your knowledge on the following types of impairment: & Sight & Hearing & \multicolumn{1}{c}{ Dual } \\
& $8.47(1.780)$ & $8.22(1.963)$ & $8.25(1.951)$ \\
Percentage rating simulation $10 / 10$ & $43.2 \%$ & $37.9 \%$ & $37.9 \%$
\end{tabular}

Influence your knowledge of the difficulties and challenges encountered Sensory impairments Cognitive impairments

by older adults with the following types of impairment:

$8.67(1.634) \quad 8.39(1.975)$

Percentage rating simulation $10 / 10$

$46.3 \%$

$41.1 \%$

Gained new insight into impairments: $n$ (\%)

\begin{tabular}{lr}
\hline Sensory & $83(87.4)$ \\
Cognitive & $83(87.4)$
\end{tabular}

On a scale of 1 (not at all) to 10 (most certainly) to what extent were the following components useful to you in practice: Mean (SD)

\begin{tabular}{ll}
\hline Sense of touch & $8.21(2.158)$ \\
Sense of smell & $8.04(2.178)$ \\
Sense of taste & $7.94(2.444)$
\end{tabular}

Did participation in this simulation influence your professional values: Mean (SD)

\begin{tabular}{lc}
\hline Empathy & $8.97(1.591)$ \\
Compassion & $9.04(1.474)$ \\
Dignity & $8.99(1.578)$ \\
Respecting choice & $9.04(1.351)$ \\
Supporting inclusion & $9.03(1.564)$ \\
Teamworking & $8.81(1.783)$
\end{tabular}

On a scale of 1 (not relevant) to 10 (extremely relevant) how critical was this simulation to your learning on sensory impairments: Mean (SD)

\begin{tabular}{ll}
\hline Critical to learning & $8.62(2.027)$
\end{tabular}

Table 4. Influence on students' learning across the cohorts.

\begin{tabular}{llll}
\hline Question & Year groups & Median & Mann-Whitney U \\
\hline Critical for learning & 1 st years & 9 & $\mathrm{U}=1348, \mathrm{Z}=2.087, \mathrm{p}=0.037$ \\
Understanding of: & $2^{\text {nd }} \& 3^{\text {rd }}$ years & 10 & \\
Sight impairments & 1 st years & 9 & $\mathrm{U}=1214, \mathrm{Z}=0.967, \mathrm{p}=0.334$ \\
& $2^{\text {nd }} \& 3^{\text {rd }}$ years & 9 & \\
Hearing impairments & 1 st years & 8 & $\mathrm{U}=1286.5, \mathrm{Z}=1.526, \mathrm{p}=0.127$ \\
& $2^{\text {nd }} \& 3^{\text {rd }}$ years & 9 & \\
Dual impairments & 1 st years & 8 & $\mathrm{U}=1334, \mathrm{Z}=1.899, \mathrm{p}=0.058$ \\
& $2^{\text {nd }} \& 3^{\text {rd }}$ years & 9 & \\
\hline
\end{tabular}




\section{Continued}

Cognitive impairments

Knowledge of:

Sight impairments

Hearing impairments

Dual impairments

Cognitive impairments

Difficulties sensory impairments

Difficulties cognitive impairments 1st years

$2^{\text {nd }} \& 3^{\text {rd }}$ years

1st years

$2^{\text {nd }} \& 3^{\text {rd }}$ years

1 st years

$2^{\text {nd }} \& 3^{\text {rd }}$ years

1st years

$2^{\text {nd }} \& 3^{\text {rd }}$ years

1st years

$2^{\text {nd }} \& 3^{\text {rd }}$ years

1st years

$2^{\text {nd }} \& 3^{\text {rd }}$ years

1st years

$2^{\text {nd }} \& 3^{\text {rd }}$ years
8

10

$\mathrm{U}=1324.5, \mathrm{Z}=1.844, \mathrm{p}=0.065$

9

$\mathrm{U}=1278, \mathrm{Z}=1.478, \mathrm{p}=0.139$

$\mathrm{U}=1254, \mathrm{Z}=1.272, \mathrm{p}=0.203$

8

$\mathrm{U}=1273, \mathrm{Z}=1.417, \mathrm{p}=0.157$

$\mathrm{U}=1124.5, \mathrm{Z}=0.256, \mathrm{p}=0.798$

8.5

$\mathrm{U}=1169.5, \mathrm{Z}=0.612, \mathrm{p}=0.541$

\subsection{Content Analysis}

Three broad themes emerged from the free text responses (as shown in Figure 1): knowledge and understanding, experiential insight, and learning for practice. Participants' responses are identified by year and field of practice (A-Adult Nursing, MH-Mental Health Nursing).

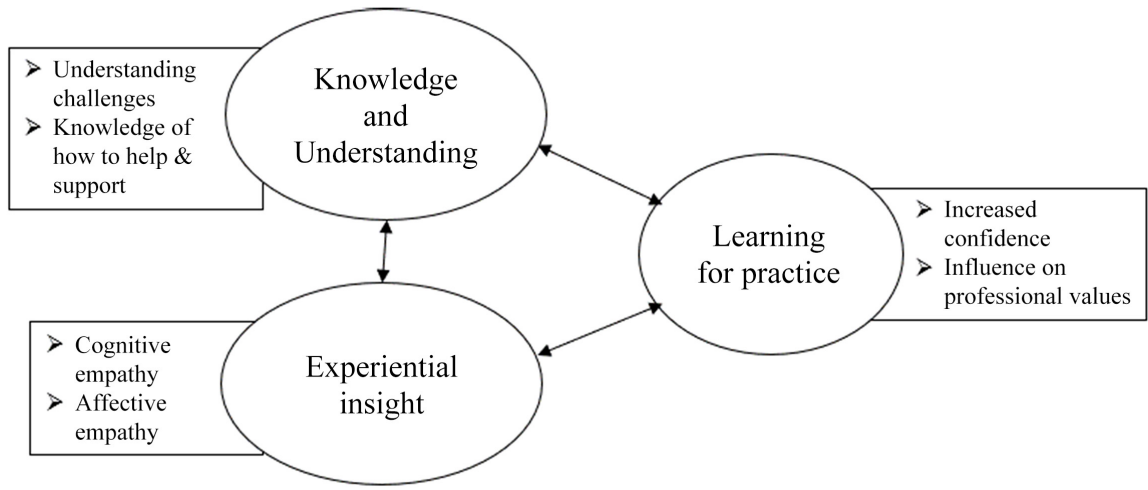

Figure 1. Key Themes (and sub-themes) as identified by the students.

\subsubsection{Knowledge and Understanding}

Students reported increased knowledge and understanding on sensory and cognitive impairments having participated in the simulation as also corroborated in the survey findings. This included: understanding of the difficulties and challenges encountered by older people living with these impairments, and knowledge of how to help and support people living with these challenges.

1) Understanding challenges 
Students noted increased understanding of the difficulties people with these impairments faced; "(more) understanding of challenges a person could have" $(1 \mathrm{~A})$ and reflected on the impact these impairments can have on everyday life: "everyday tasks can become very difficult" (1A); "the practical challenges faced with tasks that I take for granted as simple" (2A); "understanding of what might be difficult-things $P d$ not thought of (2A). Their increased understanding ranged from a generic understanding: "clearer understanding of impairments" $(2 \mathrm{~A})$, through to more specific understanding and the complexities involved: "more in depth understanding about vision and hearing loss" (1A); "I am more aware of different dysphasias and how they can affect processing" (2A), "made me aware people can hallucinate" (1A).

2) Knowledge of how to help and support

Students reported new knowledge around how to help: "helped me understand how to help people" (1A), how to support those with a variety of and multiple impairments "how to treat someone with a dual impairment" (1 MH) and knowledge of assistive aids: "(learnt about) some of the tools that can be put in place" (1A). Students also learnt techniques to help with communication: "have better perception of how you need to adjust communication to help or understand" (2A). They also reported learning other ways to help such as: "how important routine is" (1A), "how much aid people needed to eat" (1 MH) and the importance of allowing extra time: "I learnt they may need more time, so never to rush someone or get frustrated” (1A).

\subsubsection{Experiential Insight}

Experiential insight was gained because of first-hand experience of these impairments within the simulation. Sub-themes fell within two broad categories: cognitive empathy and affective empathy.

1) Cognitive Empathy

Students reported that the simulation enabled them to see alternative perspectives to appreciate some of the difficulties people face living with impairments "understanding and experiencing the difficulties person with sensory impairment has with everyday tasks" (1A). Others noted experiencing an approximation with these impairments was more powerful than just hearing about it: "understanding the difficulties they face by actually seeing what it s like rather than being told" (1A); "gave me the opportunity to put myself in their shoes and see what I actually needed to help with" (1A); "Although I had seen different colour plates etc, it was only through experience I fully understood the difficulties of sight impairment" (2A); "I was surprised that touch was affected" (2A).

\section{2) Affective Empathy}

Students reported insight into the emotional challenges and connect with some of the emotions and feelings faced by those living with these impairments and reflected on general emotional impacts: "wider knowledge of emotions someone with sensory impairments can have doing activities" (2A) and also experienced specific emotions such as frustration: "understand by experience how 
they really feel-all the difficulties and frustrations of not accomplishing simple tasks" (1A); anxiety: "feeling disadvantaged was very intimidating and caused increased anxiety" (3A) and fear: "how disorientating and scary having cognitive impairment can be" (1 MH).

\subsubsection{Learning for Practice}

Students provided evidence that the simulation had influenced their clinical practice in two main ways-increased confidence in their ability to help and support people and influence on their professional values

1) Increased confidence

Students felt more confident in their ability to work with people with these impairments, "gave me confidence to seek out opportunities where I could work with people with dementia" (1 $\mathrm{MH})$, "was able to have meaningful conversation with someone with dementia" (1 $\mathrm{MH})$. They felt better prepared to identify problems: " $P m$ better able to identify what might cause difficulties and put things in place to lessen" (2A); "understanding what it s like to not hear certain things changed the way I spoke to patients" (1A) and they felt confident to transfer their learning to practice-to help with signposting to sensory aids: "was able to recommend specific tools I had seen to make everyday activities easier" (3A); communication: "speaking to someone with hearing impairment clearly and they can see my face and mouth" (1A); "giving clear easy to follow instructions to a person with cognitive impairments so they don't get confused" (1A) and feeding: "patience and better skills when assisting with feeding" (3A).

2) Influence on professional values

The simulation influenced students' professional values and principles with students noting increased empathy: "increased ability to empathise" (1 $\mathrm{MH})$, compassion: "increased my level of understanding and compassion for those with cognitive impairments" (1A), patience: "being more patient when supporting patients" (2MH). They also developed stronger commitments to inclusion: " $I$ am able to be more inclusive to patients with cognitive impairments" (1A) and promoting choice: "help prompt an individual s choice in activities or order of activities" (2A); "importance of giving choice to those with dementia/impairment" (1 MH).

\section{Discussion}

This study has shown that a low-tech and easy to implement simulation on sensory and cognitive impairments was critical to nursing students' learning and was reported to be influential on their practice. The simulation was well received, and impacted positively on students' knowledge, understanding and skills in assisting patients with sensory, cognitive, or dual impairments.

Following simulation activities, students reported difficulties and frustrations encountered, which they felt provided lived experience of older adults with acquired sensory or cognitive impairment/s. Students identified that the opportu- 
nity to experience this from an alternative perspective was key in developing both cognitive and affective empathy which is in line with findings reported by Chen et al. [18] and Shao et al. [33] regarding the benefits of simulation in healthcare education.

Kishita et al. [2] reported that anxiety about ageing can result in negative attitudes towards older people and poor recognition of complex issues. Students in this study confirmed that the simulation enhanced their knowledge and provided insights that made them feel more confident in their ability to identify potential challenges for patients in their care. Students also reported increased confidence when identifying aids and skills to overcome barriers, for example creating communication sheets using pictures of patients' own belongings, being more aware of where they are placing things for patients with visual impairments to reach with ease or feeling confident enough to recommend tools to make everyday activities easier. They highlighted the importance of patience, respecting patients' choices, and inclusion. As a result of this improved confidence, some students actively sought additional clinical experience to care for people living with dementia that they previously had feared.

This study builds on the findings of Levett-Jones et al. [20] and has demonstrated that simulation of sensory and cognitive impairments is an effective learning experience for undergraduate nursing students. This paper reports on the experiences of 3 cohorts of students and found that they consistently rated the simulation to be valuable to their learning, facilitated an increase in knowledge, understanding and insight into sensory and cognitive impairments in older adults. A criticism of previous studies that have considered empathy is that there have not been many with longer term follow up to identify if the impact of training on practice lasts beyond the short term [34]. Whilst numbers of Year 2 and 3 students were smaller in this study, Mann-Whitney u-tests show no difference between new nursing students and those with more experience with regards to their understanding and knowledge of these impairments. However, the more experienced students rated the simulation as being more critical for learning than the first-year students. This could possibly suggest that the simulation training has sustained impact on student nursing practice up to two years post simulation experience.

Simulation as a method of teaching is not without criticism. Writers such as French [35], Burgstahler and Doe [36], Silverman [37] and Silverman et al. [38] have warned that disability simulation can result in participants perceiving people with disabilities as being helpless and needing pity and paternalistic help. The unintended learning from simulation can result in negative attitudes and uncomfortableness around disabled people [37]. Whilst it is true that we see attitudes that could be construed as pity, we also see evidence of understanding. In contrast to the assertion by French [35] we have reported evidence of positive changes to behaviour as a result of the simulation experience, participants found ways to help patients maintain independence, by respecting choice, building inclusion and allowing more time for tasks. 
In addition, this simulation has been designed to address many of the concerns raised in the literature. The simulation is intended not to simulate the experiences of people with long term disability but rather those of older people with acquired impairments. The students are also given the opportunity to experience how simple aids can improve independence [39].

The simulation pre-brief includes the caveat that the workshop can in no way mimic the everyday lived experience of sensory impairments. Students are encouraged to reflect and debrief after each station and a collective debrief at the end [36] facilitates students to discuss their feelings, emotions, challenges experienced and the transferability of learning from each station to their practice both from the perspective of a service user and a nurse.

\section{Limitations}

The original study design intended to include further qualitative evaluation via focus groups. These were not possible due to the evolution of the COVID-19 pandemic. Qualitative insights and themes were obtained from free-text responses to the survey, but these do not provide the same depth of information as focus groups may have done. Student participation decreases for each cohort as they progress further in their training and from simulation. This is perhaps not surprising as the simulation was just 4 months prior to the first-year students completing the survey but 16 and 28 months for second and third years, respectively. Although results show no difference between ratings by first versus second/third year students, with regards to knowledge and understanding, there is a difference with regards to perception of criticality for learning, with second and third years rating it higher. We do however have to consider that respondents are self-selecting and perhaps the lower number of participants from the $2^{\text {nd }}$ and $3^{\text {rd }}$ year cohorts could be suggestive of perceived usefulness or competing demands on students' time as they progress on the programme.

\section{Conclusion}

This study was built on previous reporting [31] of the development and implementation of an innovative low fidelity simulation of sensory impairments in older adults with undergraduate nursing students. Findings from this study suggest that this pedagogical approach can be effective at providing knowledge, understanding and insight (cognitive and affective empathy) influencing foundational values in nursing. Students reported increased knowledge of different impairments and valued the simulation as a part of their learning with transferrable skills and values to support patients in clinical practice.

\section{Funding}

This project was supported by the Learning \& Teaching Academy Scholarship Fund from University of the Highlands \& Islands. The funder played no role in the design, data collection, analysis or submission of this paper. 


\section{Conflicts of Interest}

The authors declare no conflicts of interest regarding the publication of this paper.

\section{References}

[1] United Nations, Department of Economic and Social Affairs, Population Division (2017) World Population Ageing 2017-Highlights (ST/ESA/SER.A/397).

[2] Kishita, N., Fisher, P. and Laidlaw, K. (2015) What Are the Attitudes of Different Age Groups towards Contributing and Benefitting from the Wider Society and How Are These Experienced by Individuals in Those Age Groups? Looking forward to 2025 and 2040, How Might These Evolve? Government Office for Science.

[3] World Health Organisation (2018) Blindness and Vision Impairment Factsheet WHO.

https://www.who.int/news-room/fact-sheets/detail/blindness-and-visual-impairme nt

[4] World Health Organisation (2019) Deafness and Hearing Loss Factsheet WHO. https://www.who.int/news-room/fact-sheets/detail/deafness-and-hearing-loss

[5] World Health Organisation (2019) Dementia Factsheet WHO. https://www.who.int/news-room/fact-sheets/detail/dementia

[6] Tseng, Y.-C., Liu, S.H.-Y., Lou, M.-F. and Huang, G.-S. (2018) Quality of Life in Older Adults with Sensory Impairments: A Systematic Review. Quality of Life Research, 27, 1957-1971. https://doi.org/10.1007/s11136-018-1799-2

[7] Alhusein, N., Macaden, L., Smith, A., Stoddart, K.M., Taylor, A.J., Killick, K., Kroll, T. and Watson, M.C. (2018) "Has She Seen Me?": A Multiple Methods Study of the Pharmaceutical Care Needs of Older People with Sensory Impairment in Scotland. BMJ Open, 8, e023198. https://doi.org/10.1136/bmjopen-2018-023198

[8] Cupples, M.E., Hart, P.M., Johnston, A. and Jackson, A.J. (2012) Improving Healthcare Access for People with Visual Impairment and Blindness. BMJ, 344, e542. https://doi.org/10.1136/bmj.e542

[9] Boyd, C.M., Wolff, J.L., Giovannetti, E., Reider, L., Weiss, C., Xue, Q.L., Leff, B., Boult, C., Hughes, T. and Rand, C. (2014) Healthcare Task Difficulty among Older Adults with Multimorbidity. Medical Care, 52, S118. https://doi.org/10.1097/MLR.0b013e3182a977da

[10] Lugo-Palacios, D.G. and Gannon, B. (2017) Health Care Utilisation amongst Older Adults with Sensory and Cognitive Impairments in Europe. Health Economics Review, 7, 44. https://doi.org/10.1186/s13561-017-0183-1

[11] Campbell, V.A., Crews, J.E., Moriarty, D.G., Zack, M.M. and Blackman, D.K. (1999) Surveillance for Sensory Impairment, Activity Limitation, and Health-Related Quality of Life among Older Adults-United States, 1993-1997. Morbidity and Mortality Weekly Report. CDC Surveillance Summaries, 48, 131-156.

[12] Hietanen, A., Era, P., Henrichsen, J., Rosenhall, U., Sorri, M. and Heikkinen, E. (2005) Hearing among 75-Year-Old People in Three Nordic Localities: A Comparative Study. La audición en personas de 75 años en tres comunidades nórdicas: Un estudio comparativo. International Journal of Audiology, 44, 500-508. https://doi.org/10.1080/14992020500189112

[13] Raina, P., Wong, M. and Massfeller, H. (2004) The Relationship between Sensory Impairment and Functional Independence among Elderly. BMC Geriatrics, 4, Article No. 3. https://doi.org/10.1186/1471-2318-4-3 
[14] Fagerström, C., Persson, H., Holst, G. and Hallberg, I.R. (2008) Determinants of Feeling Hindered by Health Problems in Daily Living at 60 Years and Above. Scandinavian Journal of Caring Sciences, 22, 410-421. https://doi.org/10.1111/j.1471-6712.2007.00545.x

[15] Gopinath, B., McMahon, C.M., Burlutsky, G. and Mitchell, P. (2016) Hearing and Vision Impairment and the 5-Year Incidence of Falls in Older Adults. Age and Ageing, 45, 409-414. https://doi.org/10.1093/ageing/afw022

[16] Shukla, A., Harper, M., Pedersen, E., Goman, A., Suen, J.J., Price, C., Applebaum, J., Hoyer, M., Lin, F.R. and Reed, N.S. (2020) Hearing Loss, Loneliness, and Social Isolation: A Systematic Review. Otolaryngology-Head and Neck Surgery, 162, 622-633. https://doi.org/10.1177/0194599820910377

[17] Nursing Midwifery Council (2018) The Code: Professional Standards of Practice and Behaviour for Nurses, Midwives and Nursing Associates. NMC.

[18] Chen, A.M.H., Kiersma, M.E., Yehle, K.S. and Plake, K.S. (2015) Impact of the Geriatric Medication Game ${ }^{\circledast}$ on Nursing Students Empathy and Attitudes toward Older Adults. Nurse Education Today, 35, 38-43.

https://doi.org/10.1016/j.nedt.2014.05.005

[19] Ward, J., Cody, J., Schaal, M. and Hojat, M. (2012) The Empathy Enigma: An Empirical Study of Decline in Empathy among Undergraduate Nursing Students. Journal of Professional Nursing, 28, 34-40. https://doi.org/10.1016/j.profnurs.2011.10.007

[20] Levett-Jones, T., Cant, R. and Lapkin, S. (2019) A Systematic Review of the Effectiveness of Empathy Education for Undergraduate Nursing Students. Nurse Education Today, 75, 80-94. https://doi.org/10.1016/j.nedt.2019.01.006

[21] Wilford, A. and Doyle, T.J. (2006) Integrating Simulation Training into the Nursing Curriculum. British Journal of Nursing, 15, 926-930. https://doi.org/10.12968/bjon.2006.15.17.21907

[22] Nursing and Midwifery Council (2018) Realising Professionalism: Standards for Education and Training. London, United Kingdom.

[23] Kelly, M.A., Berragan, E., Husebø, S.E. and Orr, F. (2016) Simulation in Nursing Education-International Perspectives and Contemporary Scope of Practice. Journal of Nursing Scholarship, 48, 312-321. https://doi.org/10.1111/jnu.12208

[24] Pearson, E. and Mclafferty, I. (2011) The Use of Simulation as a Learning Approach to Non-Technical Skills Awareness in Final Year Student Nurses. Nurse Education in Practice, 11, 399-405. https://doi.org/10.1016/j.nepr.2011.03.023

[25] Gore, T., Hunt, C.W., Parker, F. and Raines, K. (2011) The Effects of Simulated Clinical Experiences on Anxiety: Nursing Students' Perspectives. Clinical Simulation in Nursing, 7, 175-180. https://doi.org/10.1016/j.ecns.2010.02.001

[26] Burke, H. and Mancuso, L. (2012) Social Cognitive Theory, Metacognition, and Simulation Learning in Nursing Education. Journal of Nursing Education, 51, 543-548. https://doi.org/10.3928/01484834-20120820-02

[27] Haugland, V.L. and Reime, M.H. (2018) Scenario-Based Simulation Training as a Method to Increase Nursing Students' Competence in Demanding Situations in Dementia Care. A Mixed Method Study. Nurse Education in Practice, 33, 164-171. https://doi.org/10.1016/j.nepr.2018.08.008

[28] Mcgaghie, W.C., Draycott, T.J., Dunn, W.F., Lopez, C.M. and Stefanidis, D. (2011) Evaluating the Impact of Simulation on Translational Patient Outcomes. Simulation in Healthcare. The Journal of the Society for Simulation in Healthcare, 6, S42-S47. https://doi.org/10.1097/SIH.0b013e318222fde9 
[29] Humes, L.E., Busey, T.A., Craig, J. and Kewley-Port, D. (2013) Are Age-Related Changes in Cognitive Function Driven by Age-Related Changes in Sensory Processing? Attention, Perception, and Psychophysics, 75, 508-524. https://doi.org/10.3758/s13414-012-0406-9

[30] Kiely, K., Anstey, K. and Luszcz, M. (2013) Dual Sensory Loss and Depressive Symptoms: The Importance of Hearing, Daily Functioning, and Activity Engagement. Frontiers in Human Neuroscience, 7, 837.

https://doi.org/10.3389/fnhum.2013.00837

[31] Macaden, L., Smith, A. and Croy, S. (2017) Simulation on Sensory Impairment in Older Adults: Nursing Education. British Journal of Nursing, 26, 1057-1064.

https://doi.org/10.12968/bjon.2017.26.19.1057

[32] Ketso (2014) Ketso: The Hands-On Kit for Creative Engagement. http://www.ketso.com

[33] Shao, Y.N., Sun, H.M., Huang, J.W., Li, M.L., Huang, R.R. and Li, N. (2018) Simulation-Based Empathy Training Improves the Communication Skills of Neonatal Nurses. Clinical Simulation in Nursing, 22, 32-42.

https://doi.org/10.1016/j.ecns.2018.07.003

[34] Bas-Sarmiento, P., Fernández-Gutiérrez, M., Díaz-Rodríguez, M., Carnicer-Fuentes, C., Castro-Yuste, C., García-Cabanillas, M.J., Gavira-Fernández, C., de los Ángeles Martelo-Baro, M., Paloma-Castro, O., del Carmen Paublete-Herrera, M. and Rodríguez-Cornejo, M.J. (2019) Teaching Empathy to Nursing Students: A Randomised Controlled Trial. Nurse Education Today, 80, 40-51. https://doi.org/10.1016/j.nedt.2019.06.002

[35] French, S. (1992) Simulation Exercises in Disability Awareness Training: A Critique. Disability, Handicap and Society, 7, 257-266. https://doi.org/10.1080/02674649266780261

[36] Burgstahler, S. and Doe, T. (2004) Disability-Related Simulations: If, When, and How to Use Them in Professional Development. Review of Disability Studies, 1, 4-17.

[37] Silverman, A.M. (2015) The Perils of Playing Blind: Problems with Blindness Simulation and a Better Way to Teach about Blindness. Journal of Blindness Innovation and Research. https://doi.org/10.5241/5-81

[38] Silverman, A.M., Gwinn, J.D. and Van Boven, L. (2015) Stumbling in Their Shoes: Disability Simulations Reduce Judged Capabilities of Disabled People. Social Psychological and Personality Science, 6, 464-471. https://doi.org/10.1177/1948550614559650

[39] Silverman, A.M., Pitonyak, J.S., Nelson, I.K., Matsuda, P.N., Kartin, D. and Molton, I.R. (2018) Instilling Positive Beliefs about Disabilities: Pilot Testing a Novel Experiential Learning Activity for Rehabilitation Students. Disability and Rehabilitation, 40, 1108-1113. https://doi.org/10.1080/09638288.2017.1292321 